Research Article

\title{
Ascorbic Acid as an Inhibitor for SARS-CoV-2 Virus Reproduction: A Theoretical Approach
}

\author{
Mohammed Abed Jawad, Abed ] Kadhim
}

Al-Nisour University College, Iraq.

DOI: https://doi.org/10.24321/0019.5138.202155

\section{I $\quad \mathbf{N} \quad \mathbf{F} \quad \mathbf{O}$}

\author{
Corresponding Author: \\ Mohammed Abed Jawad, Al-Nisour University \\ College, Iraq. \\ E-mail Id: \\ mohammed.a.medical.lab@nuc.edu.iq \\ Orcid Id: \\ https://orcid.org/0000-0002-0219-086X \\ How to cite this article:
}

Jawad MA, Kadhim AJ. Ascorbic Acid as an Inhibitor for SARS-CoV-2 Virus Reproduction: A Theoretical Approach. J Commun Dis. 2021;53(3): 181-185.

Date of Submission: 2021-08-04

Date of Acceptance: 2021-08-26

\author{
$\begin{array}{llllllll}\mathbf{A} & \mathbf{B} & \mathbf{S} & \mathbf{T} & \mathbf{R} & \mathbf{A} & \mathbf{C} & \mathbf{T}\end{array}$
}

In the present study, ascorbic acid's or Vitamin C's influence (VC) in inhibition of SARS-CoV-2 virus reproduction was investigated. Gaussian 09 with a basis set of 6-311G (d, p), MGL tools, DSV, and LigPlus software were used. According to the Total Electron Density (TED) and Millikan charges, the active sites for adsorption were determined. Further, the docking study had clearly revealed the role of $\mathrm{VC}$ in inhibition of the virus reproduction in accordance with binding energy (Eb) and ligand efficiency (LE). The vitamin's interaction with the virus's spikes may limit its replication or provide the immune system sufficient time to recognize the infection, which enhances the possibility of producing appropriate antibodies.

Keywords: COVID-19, Vitamin C, DFT, Docking, TED

\section{Introduction}

Ascorbic acid is a water-soluble vitamin that is required by the body. It is naturally found in fresh vegetables and fruits and is found in organs like kidneys and liver. This vitamin is required for the survival of a broad range of multicellular animals, most notably humans. ${ }^{1}$ Numerous researchers, most notably Linus Pauling, have found that high doses of vitamin $\mathrm{C}$ are directly antiviral. ${ }^{2}$ In vitro studies have demonstrated that extremely high doses of vitamin $\mathrm{C}$ are effective in the presence of free copper and/or iron, most likely via the production of hydrogen peroxide and other radical species. ${ }^{3,4}$

Low pH may also have improved vitamin C's antiviral activity in vitro. Vitamin C, on the other hand, is extremely unlikely to be directly veridical in vivo. Vitamin $C$ is an effective antioxidant; it has been shown that at therapeutic quantities, it may display paradoxical pro-oxidant characteristics (the formation of reactive oxygen species) through transition metal reduction. ${ }^{5}$ Nonetheless, one study found that it reduced viral load in Epstein-Barr virus (EBV)-infected cells, ${ }^{6}$ which means the presence of a second mechanism. Cinatl and colleagues reported that pre-treatment of human foreskin fibroblast and endothelial cells with vitamin $C$ before cytomegalovirus (CMV) infection dramatically decreased viral antigen expression and viral load in the cells. ${ }^{7}$ This finding was not replicated after viral infection with vitamin C. The researchers discovered that this effect was most likely caused by vitamin C's immunomodulatory qualities rather than direct antiviral action. Vitamin $C$ concentrations are notably high in leucocytes, lymphocytes, and macrophages. Vitamin C enhances the Chemotaxis, neutrophil phagocytosis, and oxidative death, as well as lymphocyte proliferation. ${ }^{8,9}$

Following the emergence of the COVID-19 pandemic in 2019, many treatment regimens have been researched for compassionate use, except for remdesivir, which had promising outcomes and was granted emergency 
permission by the Food and Drug Administration (FDA) for the treatment of this pandemic. ${ }^{10}$ As a result, supportive care, which may include micronutrient supplements such as vitamin C, has become an essential component of COVID-19 therapy. The vitamin levels in serum and leukocytes are reduced during the acute stage of illness. ${ }^{11,12}$ Clinical trials have established that supplementing with a high dosage of vitamin C decreases the severity and duration of respiratory viral infections. ${ }^{13}$ In light of these results, vitamin $\mathrm{C}$ may be utilized to treat COVID-19, since it may boost the immune response to the new virus (SARS-CoV-2).

While the virus causes some of the pathological damage produced by SARS-CoV-2 infection, the majority is produced by a huge host immunological response and oxidative stressmediated by free radical production. ${ }^{13}$ Infection with SARSCoV-2 causes an increase in proinflammatory cytokines, termed cytokines storm, and increased generation of reactive oxygen species, both of which cause significant lung infection and the development of adult respiratory distress syndrome (ARDS). ${ }^{14}$ Septic shock, which is a primary cause of ICU admission and death in patients over 60 years old, may develop from ARDS. ${ }^{15,16}$ Vitamin $C$ is a powerful antioxidant as well as an immunomodulatory, ${ }^{17-19}$ so it could be utilized to treat and prevent COVID-19-related problems.

Since vitamin $C$ is often utilized as a supportive supplement in the treatment of the virus. In the present work, we reported a potential mechanism for vitamin C's action on the protein's membrane of the SARS-CoV- 2 virus. This suggests that one of vitamin C's effects is mediated by the reduction of coronavirus viral spikes, which may assist in decreasing viral adsorption or could inhibit the virus reproduction.

\section{Computational Approach}

The structure of the protein is downloaded from RCSB (Research Collaboratory for Structural Bioinformatics). ${ }^{20}$ Auto docking was carried out utilizing tools from the Molecular Graphics Laboratory (MGL). Autodock technique were used to separate the coordinates of the spike structure and the ligand (Vitamin C) (ADT, version 1.5.6). By adding all hydrogen atoms, Gasteiger charges, the SARS-CoV-2 spike glycoprotein-S1 and ligand structures were converted to a format accepted by the ADT (*.pdbqt files).

Unless the user indicates otherwise, the Autodock will frequently attempt to determine the molecule's root, so the Autodock chose the root on its own. Auto grid (version 4.2.6) was used to calculate atom-specific affinity maps, electrostatic and desolation potentials for all ligand atoms.23 Before docking calculations, VC was optimized in the gas phase with no symmetry constraints, Figure 1 depicts the optimal structure of VC, and Table 1 contains their coordinates. Using the unrestricted DFT approach and the 6-311G $(d, p)$ basis set, the molecular electrostatic potential (MEP) was also explored..$^{24,25}$

Table I.Cartesian Coordinates of VC Structure

\begin{tabular}{|c|c|c|c|c|}
\hline \multirow{2}{*}{$\begin{array}{c}\text { Center } \\
\text { number }\end{array}$} & \multirow{2}{*}{ Atomic } & \multicolumn{3}{|c|}{ Coordinates (Angstroms) } \\
\hline & & $\mathbf{x}$ & $\mathbf{Y}$ & $\mathbf{Z}$ \\
\hline 1. & 6 & 0.508700 & 0.563300 & -0.420800 \\
\hline 2. & 6 & 0.910500 & -0.856000 & -0.101300 \\
\hline 3. & 6 & 2.180000 & -0.872600 & 0.303700 \\
\hline 4. & 6 & 2.614900 & 0.405500 & 0.264800 \\
\hline 5. & 8 & 1.686800 & 1.315300 & -0.154000 \\
\hline 6. & 8 & 3.755800 & 0.664500 & 0.585600 \\
\hline 7. & 8 & 2.934100 & -1.928800 & 0.675600 \\
\hline 8. & 8 & 0.139500 & -1.957800 & -0.225000 \\
\hline 9. & 6 & -0.643100 & 1.086900 & 0.424000 \\
\hline 10. & 6 & -1.960700 & 0.370300 & 0.195400 \\
\hline 11. & 8 & -2.974400 & 1.117800 & 0.836700 \\
\hline 12. & 1 & 0.274000 & 0.648800 & -1.507200 \\
\hline 13. & 8 & -0.859200 & 2.439900 & 0.096200 \\
\hline 14. & 1 & 3.821000 & -1.584100 & 0.880100 \\
\hline 15. & 1 & 0.692200 & -2.719600 & 0.022300 \\
\hline 16. & 1 & -0.404848 & 1.678960 & 1.282837 \\
\hline 17. & 1 & -2.219900 & 0.313200 & -0.884900 \\
\hline 18. & 1 & -1.973000 & -0.649400 & 0.637100 \\
\hline 19. & 1 & -3.821000 & 0.678100 & 0.739900 \\
\hline 20. & 1 & -1.678100 & 2.719600 & 0.515800 \\
\hline
\end{tabular}

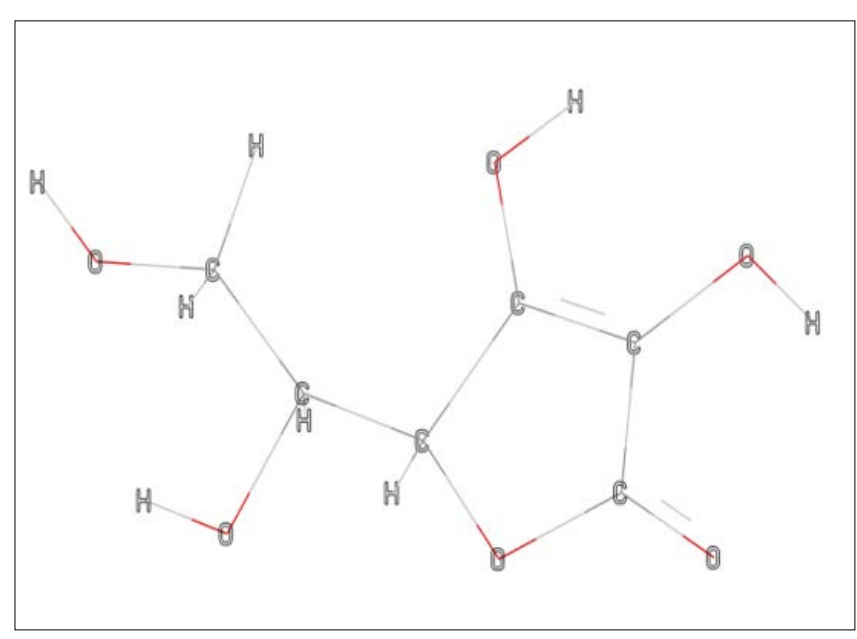

Figure I.VC Structure

\section{Results and Discussion}

\section{Interaction of VC with the Spikes}

The suggested mechanism of SARS-CoV-2 virus inhibition is by interaction of VC with the spikes, which could enhance 
the role of immunity system. The active functional groups in $\mathrm{VC}$ are $\mathrm{OH}$ and $\mathrm{C}=\mathrm{O}$ and there are planarity in some sections, according to geometry optimization (depending on the cis and trans of atoms in the molecule, the dihedral angle of each four cis atoms is about zero, while in trans is about $180^{\circ}$ ).

Figure 2 shows the PDB structural code (6acd) and the interaction of the protein with VC. Measuring the binding energy, the affinity of vitamin $C$ to the receptor, enabled us to compare the optimum sites for linking with the protein. ${ }^{26,27}$ The binding energy range was ranging from -0.94 to $-2.17 \mathrm{Kcal} / \mathrm{mol}$. So, the best-bounded site (BS) on the protein is the one that has the highest value of the binding energy $2.17 \mathrm{kcal} / \mathrm{mol}$.

Additionally, the Ligand Efficiency (LE) of the ligand per atom attached to the receptor protein is $-0.18 \mathrm{kcal} / \mathrm{mol} .^{28,29}$ Thus, this process may give the body an additional time to produce suitable antibodies.

Table 2.Binding Energy Value and Ligand Efficiency of the Studied Inhibitor

\begin{tabular}{|c|c|c|c|c|}
\hline Comp. & $\begin{array}{c}\text { Eb (kcal/ } \\
\text { mol) }\end{array}$ & LE & -Eb range & BS \\
\hline VC & 2.17 & -0.18 & -0.94 to -2.17 & 6 \\
\hline
\end{tabular}

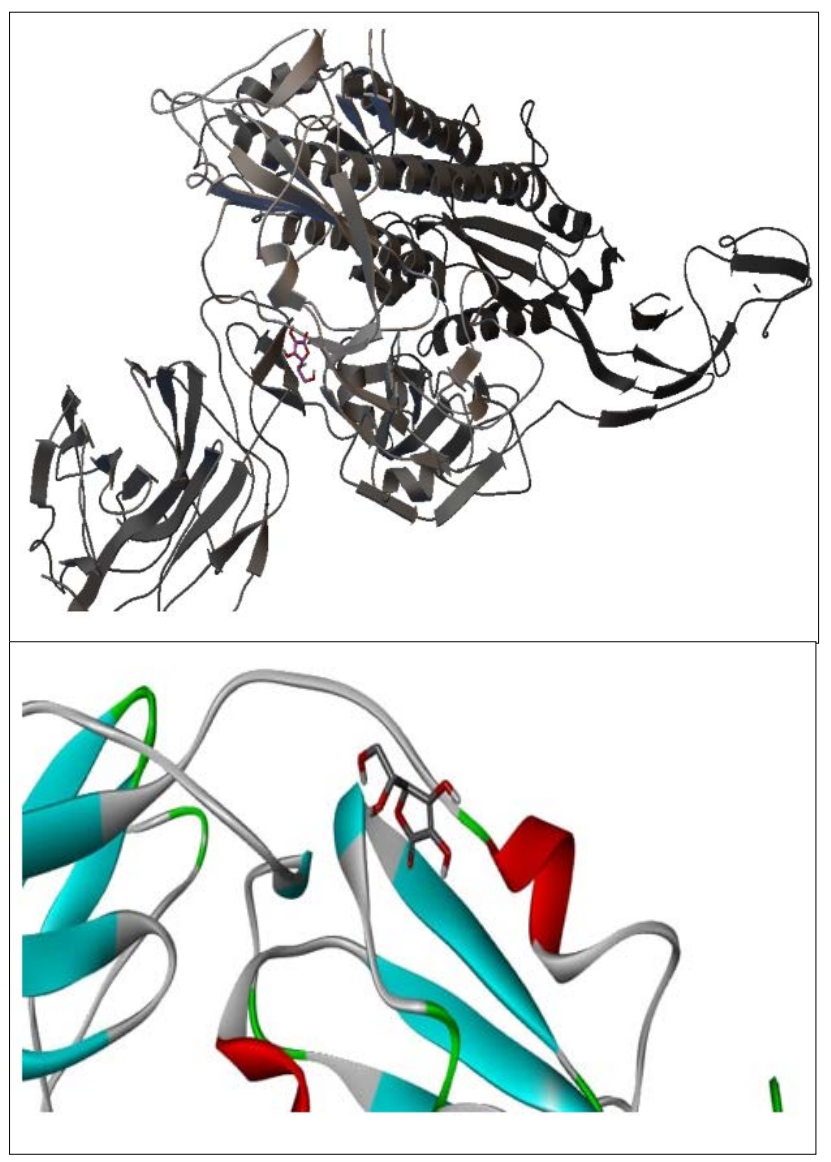

Figure 2.Interaction of VC with the Protein

\section{The Bonds of VC with Virus's Amino Acids}

By analysis of the results obtained from the DSV, LigPlus, and MGL tools, the interaction between the amino acid of the virus spike and VC is clearly revealed. The $\mathrm{OH}$ and $\mathrm{C}=\mathrm{O}$ groups form hydrogen bonds with the VAL and ASP amino acids, respectively. The bond length of VAL-HO(vc) and ASP$\mathrm{CO}(\mathrm{vc})$ are of 3.19 and $3.11 \AA$, respectively. In addition, the amino acids viz ASN, LEU, CYC, ALA, VAL, and PHE showed low effect but cannot be bypassed (Figure 3 ). The electron density of the donor atom determines the strength of the adsorption bond. The electron density on the molecule was visualized using total electron density (TED).

As shown in Figure 4, the red color represents the sites with high electronegativity, such as the $\mathrm{O}$ atoms of a hydroxyl groups $(\mathrm{OH})$. While the atoms with moderate electronegativity are represented by yellow color. In the same context, the blue region is the most favorable positive area for accepting electrons from donor atoms [30-32], as it is the lowest electronegativity.

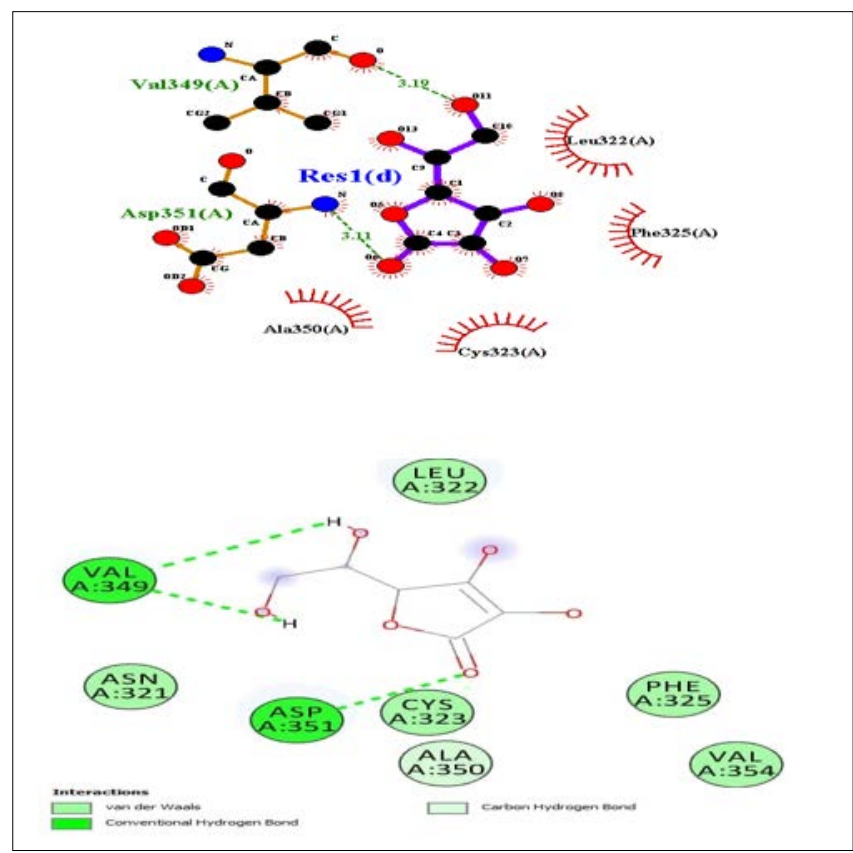

Figure 3.2D Interactions of VC with COVID- I 9 Amino Acids

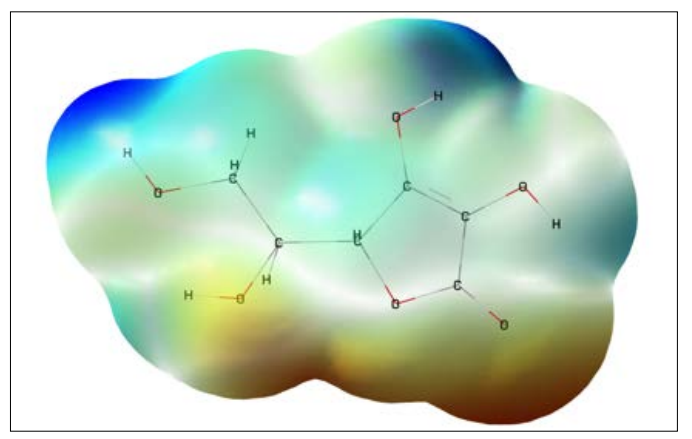

Figure 4.TED Map of VC 


\section{Local Reactivity of VC}

To investigate the localized reactivity of the studied inhibitor (nucleophilic and electrophilic centers), The DFT method used for Mulliken charges population analysis to determine the reactive centers of molecules. As a result, the molecule regions with a large electronic charge are chemically softer than those with a small electronic charge, so the electron density is significant when calculating chemical reactivity.

Interactions in chemical adsorption could be electrostatic or orbital in nature. Electrostatic interactions are driven by the electrical charges in the molecule. The physicochemical properties of compound reactions are influenced by proven charges.33, 34 As a result, the nucleophilic attack will be on the site that has the highest negative charge value. In turn, the positive charge value determines the electrophilic attack site. Therefore, the favored sites for electrophilic attack and the most reactive of $\mathrm{VC}$ are $\mathrm{C}$ and $\mathrm{H}$ atoms. The green color represents the high positive charge, so the decrease in color intensity indicates a decrease in positivity. It is found that the most reactive sites that can accept electrons for $\mathrm{VC}$ in the nucleophilic attack are $\mathrm{O}$ atoms (Figure 5).

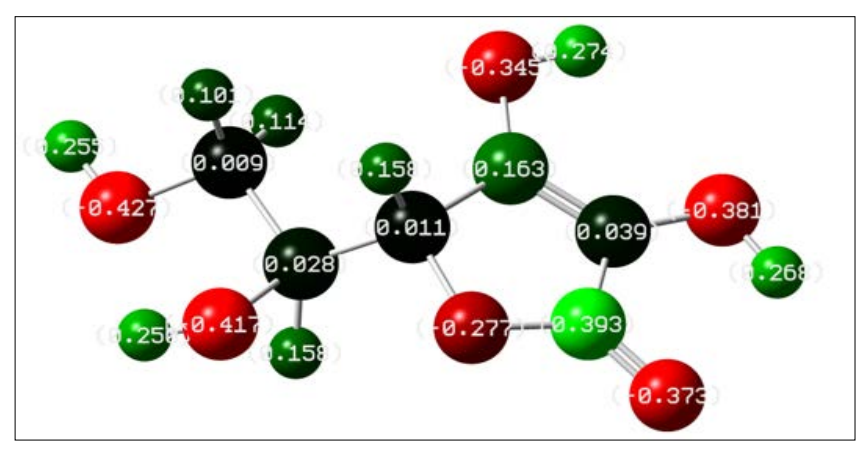

Figure 5. Millikan Charges of VC

\section{Conclusion}

A theoretical research has been undertaken to evaluate the effectiveness of ascorbic (vitamin C) as an antiviral agent against the SARS-CoV-2 virus. Computational calculations were used to investigate the binding of the vitamin with the virus's spikes. The TED revealed that the $\mathrm{OH}$ and $\mathrm{C}=\mathrm{O}$ groups in VC are the interaction sites with the virus. The binding energy reflected the high affinity of the spike proteins to the VC. The calculations showed that the VC interacts with the spikes via hydrogen bonding.

Docking study refers to the ability of VC to reduce the activity of SARS-CoV-2, depending on Eb $(-2.17 \mathrm{kcal} / \mathrm{mol}))$ and LE $(-0.18 \mathrm{kcal} / \mathrm{mol})$ values. Depending on Millikan's descriptions, the electrophilic and nucleophilic sites are (C, $\mathrm{H})$ and $(\mathrm{O})$ atoms, respectively.

\section{Conflict of Interest: None}

\section{References}

1. Food and Nutrition Board. Dietary Reference Intakes for Vitamin C, Vitamin E, Selenium, and Carotenoids. Washington, DC: National Academy Press, 2000.

2. Pauling $L$. The significance of the evidence about ascorbic acid and the common cold. Proc Natl Acad Sci U S A. 1971;68:2678-81. [PubMed] [Google Scholar]

3. While LA, Freeman CY, Forrester BD, Chappell WA. In vitro effect of ascorbic acid on infectivity of herpesviruses and paramyxoviruses. J Clin Microbiol. 1986 Oct;24(4):52731. [PubMed] [Google Scholar]

4. Klein M. The mechanism of the virucidal action of ascorbic acid. Science. 1945 Jun;101(2632):587-9. [PubMed] [Google Scholar]

5. Marik PE. Hydrocortisone, ascorbic acid and thiamine (HAT therapy) for the treatment of sepsis. Focus on ascorbic acid. Nutrients. 2018 Nov;10(11):1762. [PubMed] [Google Scholar]

6. Uesato S, Kitagawa Y, Kaijima T, Tokuda H, Okuda M, Mou XY, Mukainaka T, Nishino H. Inhibitory effects of 6-O-acylated L-ascorbic acids possessing a straight- or branched-acyl chain on epstein-barr virus activation. Cancer Lett. 2001 May;166(2):143-6. [PubMed] [Google Scholar]

7. Cinatl J, Cinatl J, Weber B, Rabenau H, Gümbel HO, Chenot JF, Scholz M, Encke A, Doerr HW. In vitro inhibition of human cytomegalovirus replication in human foreskin fibroblasts and endothelial cells by ascorbic acid 2-phosphate. Antiviral Res. 1995 Aug;27(4):405-18. [PubMed] [Google Scholar]

8. Carr AC, Maggini S. Vitamin C and Immune Function. Nutrients. 2017 Nov;9(11):1211. [PubMed] [Google Scholar]

9. Leibovitz B, Siegel BV. Ascorbic acid and the immune response. Adv Exp Med Biol. 1981;135:1-25. [Google Scholar]

10. Dey S, Bishayi B. Killing of S. aureus in murine peritoneal macrophages by ascorbic acid along with antibiotics chloramphenicol or ofloxacin: correlation with inflammation. Microb Pathog. 2018 Feb;115:239-50. [PubMed] [Google Scholar]

11. Sanders J, Monogue M, Jodlowski T, Cutrell J. Pharmacologic treatments for coronavirus disease 2019 (COVID-19). JAMA. 2020 May;323(18):1824-36. [PubMed] [Google Scholar]

12. Bilbul M, Paparone P, Kim A, Mutalik S, Ernst C. Psychopharmacology of COVID-19. Psychosomatics. Psychosomatics. 2020 Sep-Oct;61(5):411-27. [PubMed] [Google Scholar]

13. Carr A, Rosengrave P, Bayer S, Chambers S, Mehrtens J, Shaw G. Hypovitaminosis $\mathrm{C}$ and vitamin C deficiency in critically ill patients despite recommended enteral and parenteral intakes. Crit Care. 2017 Dec;21(1):300. [PubMed] [Google Scholar]

14. Earar K, Arbune M, Dorobat $C$, Rusu-Negraia M, Stefanescu V, Indrei L, Schipor O, Harabor VR, Harabor 
A, Bratu AM. Biochemical effects and therapeutic application of vitamin C (C6H806) on COVID-19 infection. Rev Chim. 2020;71(5):473-8. [Google Scholar]

15. Bauer S, Kapoor A, Rath M, Thomas S. What is the role of supplementation with ascorbic acid, zinc, vitamin $\mathrm{D}$, or $\mathrm{N}$-acetylcysteine for prevention or treatment of COVID-19? Cleveland Clin J Med. 2020 Jun 8. [PubMed] [Google Scholar]

16. Wang L, Wang Y, Ye D, Liu Q. Review of the 2019 novel coronavirus (SARS-CoV-2) based on current evidence. Int J Antimicrob Agents. 2020 Jun;55(6):105948. [PubMed] [Google Scholar]

17. Wu J. Tackle the free radicals damage in COVID-19. Nitric Oxide. 2020 Sep;102:39-41. [PubMed] [Google Scholar]

18. Wang D, Hu B, Hu C, Zhu F, Liu X, Zhang J, Wang B, Xiang $\mathrm{H}$, Cheng Z, Xiong Y, Zhao Y, Li Y, Wang X, Peng Z. Clinical characteristics of 138 hospitalized patients with 2019 novel coronavirus-infected pneumonia in Wuhan, China. JAMA. 2020 Mar;323(11):1061-9. [PubMed] [Google Scholar]

19. Kakodkar P, Kaka N, Baig M. A comprehensive literature review on the clinical presentation, and management of the pandemic coronavirus disease 2019 (COVID-19). Cureus. 2020 Apr;12(4):e7560. [PubMed] [Google Scholar]

20. Colunga Biancatelli R, Berrill M, Marik P. The antiviral properties of vitamin C. Expert Rev Anti Infect Ther. 2020 Feb;18(2):99-101. [PubMed] [Google Scholar]

21. Gao Y, Lu B, Zhai J, Liu Y, Qi H, Yao Y, Chai Y-F, Shou S-T. The parenteral vitamin $C$ improves sepsis and sepsisinduced multiple organ dysfunction syndrome via preventing cellular immunosuppression. Mediators Inflamm. 2017;2017:1-12. [PubMed] [Google Scholar]

22. Boretti A, Banik B. Intravenous vitamin C for reduction of cytokines storm in acute respiratory distress syndrome. PharmaNutrition. 2020 Jun;12:100190. [PubMed] [Google Scholar]

23. Adiloğlu SI, Yu C, Chen R, Li JJ, Li JJ, Drahansky M, Paridah M, Moradbak A, Mohamed A, Owolabi, FolaLi $\mathrm{H}$ Abdulwahab Taiwo, Asniza M, Abdul Khalid SH, Sharma T, Dohare $N$, Kumari $M$, Singh UK, Khan AB, Borse MS, Patel R, Paez A, Howe A, Goldschmidt D, Corporation C, Coates J, Reading F. We are IntechOpen, the world's leading publisher of open access books built by scientists, for scientists TOP 1\%. Intech. 2012;i:13.

24. Yu JQ, Geng YL, Wang DJ, Zhao HW, Guo L, Wang $X$. Terpenes from the gum resin of Boswellia carterii and their NO inhibitory activies. Phytochem. Lett. 2018;28:59-63. [Google Scholar]

25. Sayin K, Kariper SE, Taştan M, Sayin TA, Karakaş D. Investigations of structural, spectral, electronic and biological properties of $\mathrm{N}$-heterocyclic carbene $\mathrm{Ag}(\mathrm{I})$ and Pd(II) complexes. J. Mol. Struct. 2019;1176:478-87. [Google Scholar]
26. Zimmermann-klemd AM, Reinhardt JK, Nilsu T, Morath A, Falanga CM, Schamel WW, Huber R, Hamburger M, Gründemann C. Boswellia carteri extract and 3- O -acetyl-alpha-boswellic acid suppress T cell function. Fitoterapia. 2020 Oct;146:104694. [PubMed] [Google Scholar]

27. Becke AD. Density-functional thermochemistry. III. The role of exact exchange. J. Chem. Phys. 1993;98:5648-52.

28. Lee C, Yang W, Parr RG. Development of the ColleSalvetti correlation-energy formula into a functional of the electron density. Phys Rev B Condens Matter. 1988 Jan;37(2):785-9. [PubMed] [Google Scholar]

29. Li H, Leung KS, Ballester PJ, Wong MH. istar: A web platform for large-scale protein-ligand docking. PLoS One. 2014 Jan;9(1):e85678. [PubMed] [Google Scholar]

30. Hussein EA, Shaheed IM, Hatam RS, Kadhim MM, Al-kadhum DT. Adsorption, thermodynamic and DFT studies of removal RS dye on the Iraq clay from aqueous solutions. Sys Rev Pharm. 2020;11(3):495-502. [Google Scholar]

31. Li H, Leung KS, Ballester PJ, Wong MH. istar: A web platform for large-scale protein-ligand docking. PLoS One. 2014 Jan;9(1):e85678. [PubMed] [Google Scholar]

32. Mustafa MK, Abbas WS, Ameerah MZ, Wesam RK. Inhibition of SARS-CoV-2 reproduction using Boswellia carterii: A theoretical study. J. Mol. Liq. 2021 Sep;337:116440. [Google Scholar]

33. Salman AW, Haque RA, Kadhim MM, Malan FP, Ramasami P. Novel triazine-functionalized tetra-imidazolium hexafluorophosphate salt: Synthesis, crystal structure and DFT study. J. Mol. Struct. 2019;1198:126902. [Google Scholar]

34. Radhi AH, Du EAB, Khazaal FA, Abbas ZM, Aljelawi $\mathrm{OH}$, Hamadan HD, Almashhadani HA, Kadhim MM. HOMO-LUMO Energies and geometrical structures effect on corrosion inhibition for organic compounds predict by DFT and PM3 methods. NeuroQuantology. 2020;18(1):37-45. [Google Scholar]

35. Khazaal FA, Kadhim MM, Hussein HF, Abbas ZM, Hamzah MS, Khudhair IA, Almashhadani HA, Abed HH, Saieed HS. Electronic transfers and (NLO) properties predicted by $A B$ initio methods with prove experimentally. NeuroQuantology. 2020;18(1):46-52. [Google Scholar]

36. Abdul E, Fanfoon DY, Al-uqaily RAH, Salman AM, Kadhim MM, Salman AW, Abbas ZM.1-Isoquinolinyl phenyl ketone as a corrosion inhibitor : A theoretical study. Mater Today Proc. 2021;42(5):2241-6. [Google Scholar]

37. Eva AY, Rana AA, Majid HA, Ivan HR, Mustafa MK. Electrochemical, morphological and theoretical studies of an oxadiazole derivative as an anti-corrosive agent for kerosene reservoirs in Iraqi refineries. Chem. Pap. 2019;4:9883-92. [Google Scholar] 